\title{
MODELLING HOURLY AIR TEMPERATURE, RELATIVE HUMIDITY AND SOLAR IRRADIANCE OVER SEVERAL MAJOR OIL PALM GROWING AREAS IN MALAYSIA
}

\section{CHEAH SEE SIANG*; CHRISTOPHER TEH BOON SUNG**; MOHD RAZI ISMAIL ${ }^{\ddagger}$ and MOHD RAFII YUSOP ${ }^{\ddagger}$}

\begin{abstract}
Hourly values of air temperature, relative humidity and solar irradiance are often not available in most of the oil palm growing areas in Malaysia, thus limiting research in studying how these weather variables affect oil palm growth and yield. Therefore, a study was carried out to determine the accuracy of some selected models to estimate hourly values of these weather variables in six major oil palm growing areas in Malaysia. Using daily maximum and minimum temperatures, hourly air temperature was estimated. Together with mean hourly dew point temperature, the estimated hourly air temperature was used to simulate hourly relative humidity which was subsequently used to estimate hourly total solar irradiance. The mean absolute error, root mean square error and Willmott's index of agreement within a 24-hr period for air temperature ranged from $0.5^{\circ} \mathrm{C}-0.7^{\circ} \mathrm{C}, 0.6^{\circ} \mathrm{C}-1.0^{\circ} \mathrm{C}$ and $0.81-0.84$, respectively; for relative humidity ranged from $0.8 \%-1.5 \%$, 1.0\%-2.0\% and 0.88-0.93, respectively and for total solar irradiance ranged from 83-139 W m-2, 109-178 W $m^{-2}$ and 0.66-0.75, respectively. These models thus could be used to simulate hourly air temperature, relative humidity and solar irradiance in the six major oil palm growing areas in Malaysia.
\end{abstract}

Keywords: oil palm, modelling, weather variables.

Date received: 18 March 2019; Sent for revision: 14 April 2019; Accepted: 16 June 2019.

\section{INTRODUCTION}

In crop modelling, air temperature, relative humidity, wind speed and solar irradiance data are often required as model input because these weather variables drive physiological processes such as

\footnotetext{
Sime Darby Plantation Research Sdn Bhd,

KM10, Jalan Banting-Klang,

42700 Banting, Selangor, Malaysia.

E-mail: cheah.see.siang@simedarbyplantation.com

** AgroBio Complex,

Deparment of Land Management, Faculty of Agriculture,

Universiti Putra Malaysia,

43400 UPM Serdang, Selangor, Malaysia.

‡ Institute of Tropical Agriculture and Food Security,

Universiti Putra Malaysia,

43400 UPM Serdang,

Selangor, Malaysia.
}

photosynthesis, transpiration and respiration. However, most of these weather data are not always available in most of the major oil palm growing areas in Malaysia, thus limiting research in studying how weather variables affect physiological processes of oil palm and subsequently its growth and yield. These weather data if available are often in the form of daily average (wind speed, relative humidity and solar irradiance) or daily maximum and minimum (air temperature). As highlighted by Ephrath et al. (1996), daily weather data are convenient to work with but the use of daily weather data in modelling crop responses to weather variables often results in deviations. This is because physiological processes such as photosynthesis, transpiration and respiration, respond instantaneously to weather variables and daily weather data are not sufficient to deal with these instantaneous responses. One way 
to overcome this limitation is to resort to simulating the hourly patterns of these weather variables based on available daily weather data.

Many models have been developed to estimate hourly values of air temperature (De Wit et al., 1978; Wilkerson et al., 1983; Floyd and Braddock, 1984; Wann et al., 1985; Kimball and Bellamy, 1986), solar irradiance (Bristow and Campbell, 1984; Yang and Koike, 2002; Kaplanis and Kaplani, 2007; Al Riza et al., 2011), relative humidity (Ephrath et al., 1996; Waichler and Wigmosta, 2003) and wind speed (Ephrath et al., 1996; Waichler and Wigmosta, 2003) from daily data. With modification or calibration, some of these models can be used to simulate hourly patterns of weather variables in Malaysia.

The objective of the work presented here was, thus to determine the accuracy of some selected models, with some modifications to estimate hourly values of air temperature, relative humidity and solar irradiance from data collected by standard meteorological stations. The models developed in this study are to be used in oil palm modelling work, for hourly weather prediction in estimating oil palm growth and yield responses.

\section{MATERIALS AND METHODS}

\section{Meteorological Data}

Hourly air temperature, relative humidity, dew point temperature and solar irradiance data were collected from six weather stations (WatchDog 2900ET Series, Spectrum Technologies Inc., USA) belonging to Sime Darby Plantation Research Sdn. Bhd. The geographical locations and date of measurement are given in Table 1 and Figure 1. Daily minimum air temperature $\left(T_{\min }\right)$ and maximum air temperature $\left(T_{\max }\right)$ recorded from August 2015 to July 2017 were used to predict hourly air temperature recorded in the same period. Hourly relative humidity values were computed from air vapour pressure and saturated air vapour pressure, which were computed from air and dew point temperatures. The estimated relative humidity values were then validated by hourly relative humidity recorded from August 2015 to July 2017.

Hourly solar irradiance and relative humidity recorded from August 2015 to July 2016 were used to derive an empirical equation relating sky

\section{TABLE 1. GEOGRAPHICAL LOCATIONS OF WEATHER STATIONS AND DATE OF MEASUREMENT}

\begin{tabular}{llccl}
\hline Station name & Location & Latitude, $^{\circ} \mathbf{N}$ & Longitude, $^{\circ} \mathrm{E}$ & Month \\
\hline Bukit Selarong & Kulim & 5.477902 & 100.596030 & August 2015-July 2017 \\
Seri Intan & Teluk Intan & 3.970315 & 100.980114 & August 2015-July 2017 \\
Dusun Durian & Banting & 2.800000 & 101.462000 & August 2015-July 2017 \\
Diamond Jubilee & Jasin & 2.330671 & 102.488170 & August 2015-July 2017 \\
Ulu Remis & Layang & 1.844170 & 103.466407 & August 2015-July 2017 \\
Imam & Tawau & 4.331978 & 117.834251 & August 2015-July 2017 \\
\hline
\end{tabular}

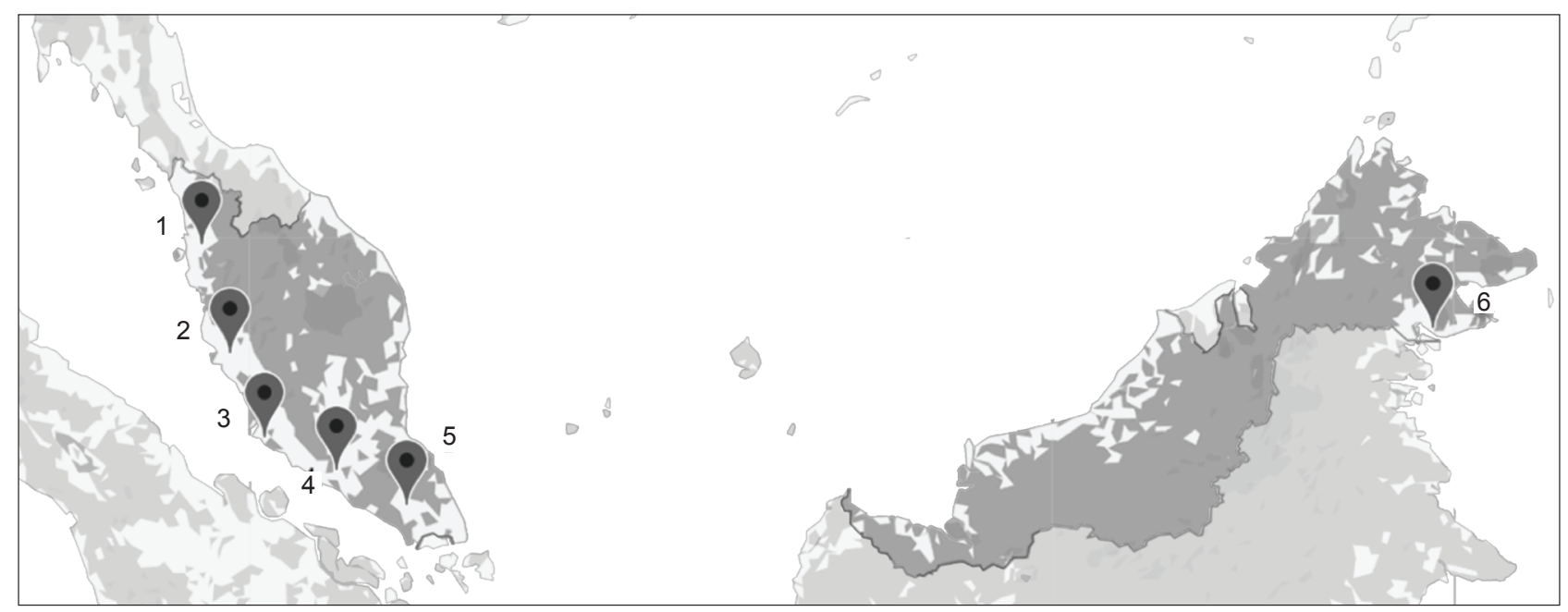

Figure 1. A Malaysian map depicting location of the six weather stations used in the present study. Stations 1, 2, 3, 4, 5 and 6 represent Bukit Selarong, Seri Intan, Dusun Durian, Diamond Jubilee, Ulu Remis and Imam, in Malaysia respectively. 
clearness index and relative humidity while data recorded from August 2016 to July 2017 were used for validation. Erroneous total solar irradiance, $I_{t}$ (which caused clearness index $>1$ ) and night data were omitted from the regression analysis.

\section{Description of Meteorological Models}

Air temperature. Depending on the location, the hourly trend of air temperature for these six stations were observed to vary sinusoidally with time during the period between $1.5 \mathrm{hr}$ after the time of minimum air temperature and time of sunset. Outside this period, air temperature was observed to change linearly with time. This trend can be described by the following mathematical relationships according to Wilkerson et al. (1983) as:

$T_{a}= \begin{cases}T_{s e t}+\frac{\left(T_{\min }-T_{s e t}\right)\left(24+t_{h}-t_{s s}\right)}{\left(t_{s r}+1.5\right)+\left(24-t_{s s}\right)} & t_{h}<\left(t_{s r}+1.5\right) \\ T_{\min }+\left(T_{\max }-T_{\min }\right) \sin \left[\frac{\pi\left(t_{h}-t_{s r}-1.5\right)}{t_{s s}-t_{s r}}\right] & \left(t_{s r}+1.5\right) \leq t_{h} \leq t_{s s} \\ T_{s e t}+\frac{\left(T_{\min }-T_{s e t}\right)\left(t_{h}-t_{s s}\right)}{\left(t_{s r}+1.5\right)+\left(24-t_{s S}\right)} & t_{h}>t_{s s}\end{cases}$

$$
T_{s e t}=T_{\min }+\left(T_{\max }-T_{\min }\right) \sin \left[\frac{\pi\left(t_{s s}-t_{s r}-1.5\right)}{t_{s s}-t_{s r}}\right]
$$

where $T_{a}$ is the air temperature at local solar time $t_{h}$ (hr); $T_{\min }$ and $T_{\max }$ are the minimum and maximum air temperature, respectively; $t_{s r}$ and $t_{s s}$ are the times of sunrise and sunset, respectively $(\mathrm{hr})$; and $T_{\text {set }}$ is the air temperature at sunset $\left(t_{s s}\right)$. All temperatures are in ${ }^{\circ} \mathrm{C}$.

Dew point temperature. The hourly dew point temperature $T_{\text {dew }}$ for these six stations were rather constant throughout the year, with mean values ranged from $23 \pm 1.5^{\circ} \mathrm{C}$ to $23.7 \pm 1.4^{\circ} \mathrm{C}$. Outliers were removed using the interquartile method. Across all six stations, the upper bound dew point temperature ranged between $25.8^{\circ} \mathrm{C}-27.3^{\circ} \mathrm{C}$ and the lower bound dew point temperature ranged between $18.7^{\circ} \mathrm{C}-20.6^{\circ} \mathrm{C}$. Dew point temperatures fall outside the upper and lower bound range were omitted. The mean values are within the range reported by Desa and Rakhecha (2006), who also observed a rather constant dew point temperature between $20^{\circ} \mathrm{C}-24^{\circ} \mathrm{C}$ when studying $24 \mathrm{hr}$ persisting dew point temperature for 24 towns across Malaysia for the 1994-2003 period. Tang and Chin (2012) also observed a rather constant mean dew point temperature of $23.4^{\circ} \mathrm{C}$ with standard deviation ranged between $0.8^{\circ} \mathrm{C}-1.5^{\circ} \mathrm{C}$ when analysing hourly weather data recorded in Subang, Malaysia. The minimum, maximum, mean and median dew point temperatures for all six stations are given in Table 2.

Relative humidity. In the computation of hourly relative humidity, we need to know the hourly dew point temperature. Since hourly dew point temperatures for all six stations were rather constant, the mean hourly dew point temperature of each station was used to compute hourly relative humidity. Knowing the hourly dew point temperature, hourly relative humidity can be computed from air vapour pressure and air saturated vapour pressure according to Ephrath et al. (1996) as:

$$
e_{a}=6.1078 \exp \left(\frac{17.269 T_{d e w, c a l}}{T_{d e w, c a l}+237.3}\right)
$$

where $e_{a}$ is the air vapour pressure (mbar); and $T_{\text {devw,cal }}$ is the calibrated dew point temperature $\left({ }^{\circ} \mathrm{C}\right)$, and it should be lower than current air temperature, $T_{a}$ :

$$
\begin{gathered}
T_{d e w, c a l}=\operatorname{MIN}\left(T_{a}, T_{d e w}\right) \\
e_{\mathrm{s}}\left[T_{\mathrm{a}}\right]=6.1078 \exp \left(\frac{17.269 T_{\mathrm{a}}}{T_{\mathrm{a}}+237.3}\right)
\end{gathered}
$$

where $e_{s}\left[T_{a}\right]$ is the function returning the air saturated vapour pressure (mbar) at air temperature $T_{a}\left({ }^{\circ} \mathrm{C}\right)$.

TABLE 2. THE MINIMUM, MAXIMUM, MEAN \pm SE AND MEDIAN DEW POINT TEMPERATURES $\left({ }^{\circ} \mathrm{C}\right)$

\begin{tabular}{lccccc}
\hline \multicolumn{1}{c}{ Station name } & $n$ & Minimum & Maximum & Mean & Median \\
\hline Bukit Selarong & 16436 & 20.3 & 26.3 & $23.4 \pm 1.1$ & 23.4 \\
Seri Intan & 16193 & 20.3 & 26.2 & $23.3 \pm 1.1$ & 23.4 \\
Dusun Durian & 11891 & 20.0 & 27.3 & $23.0 \pm 1.5$ & 23.2 \\
Diamond Jubilee & 16722 & 20.1 & 27.3 & $23.7 \pm 1.4$ & 23.7 \\
Ulu Remis & 15859 & 20.6 & 25.8 & $23.2 \pm 1.0$ & 23.2 \\
Imam & 16576 & 20.3 & 26.2 & $23.3 \pm 1.1$ & 23.3 \\
\hline
\end{tabular}




$$
R H=100\left(\frac{e_{\mathrm{a}}}{e_{\mathrm{s}}\left[T_{\mathrm{a}}\right]}\right)
$$

where $R H$ is the relative humidity (\%) for the given hour; $e_{a}$ is the air vapour pressure (mbar); and $e_{s}\left[T_{a}\right]$ is the function returning the air saturated vapour pressure (mbar) at air temperature $T_{a}\left({ }^{\circ} \mathrm{C}\right)$.

Solar irradiance. On a horizontal surface, hourly total solar irradiance can be calculated using $I_{e t}$ and $\tau$ as follows (Al Riza et al., 2011):

$$
\begin{gathered}
\frac{I_{\mathrm{t}}}{I_{\mathrm{et}}}=\tau \\
I_{\mathrm{et}}=I_{\mathrm{c}}^{\prime} \vartheta_{\mathrm{z}}
\end{gathered}
$$

where $I_{t}$ is the hourly total solar irradiance and $I_{e t}$ is the hourly extraterrestrial solar irradiance determined from Equation (3.1) (all in $\mathrm{W} \mathrm{m}^{-2}$ ); $\tau$ is the sky clearness index (or atmospheric transmittance, the ratio between $I_{t}$ and $I_{e t}$ ). The $I_{c}^{\prime}$ is the solar constant corrected for eccentricity and can be approximated as follows:

$$
I_{\mathrm{c}}^{\prime}=I_{\mathrm{c}}\left\{1+0.033 \cos \left[\frac{2 \pi\left(t_{\mathrm{d}}-10\right)}{365}\right]\right\}
$$

where $t_{d}$ is the day of year. The zenith angle $\vartheta_{z}$ is represented by the following relationship as:

$$
\cos \vartheta_{z}=\sin \lambda \cdot \sin \delta+\cos \lambda \cdot \cos \delta \cdot \cos \omega
$$

where $\lambda$ is the latitude of location, $\delta$ is the solar declination and $\omega$ is the hour angle. Al Riza et al. (2011) showed that $\tau$ can be estimated from relative humidity $(\mathrm{RH})$ and in turn be used to calculate $I_{t}$.
Linear regression was used to correlate $\tau$ and relative humidity as:

$$
\tau=\frac{I_{\mathrm{t}}}{I_{\mathrm{et}}}=a+b R H
$$

where $I_{e t}$ is the hourly extraterrestrial solar irradiance determined from Equation (3.1), $I_{t}$ and $\mathrm{RH}$ are the measured hourly total solar irradiance and relative humidity, respectively, and $a$ and $b$ are empirical coefficients. The relationship between sky clearness index and RH; and coefficient $a$ and $b$ were determined by pooling hourly meteorological data from five stations (Table 1, excluding Dusun Durian). Hourly meteorological data recorded by Dusun Durian station were excluded due to faulty pyranometer. The relationship between sky clearness index and $\mathrm{RH}$ is shown in Figure 2; and coefficient $a$ and $b$ determined were 1.1857 and -0.0112, respectively. Equations (3.0) to (3.4) are then used to simulate hourly total solar irradiance for all six stations for the period from August 2016 to July 2017.

\section{Model Evaluation}

Model performances were evaluated by the mean absolute error (MAE), root mean square error (RMSE) and Willmott's index of agreement $(d)$ between observed and estimated values (Willmott and Matsuura, 2005). MAE measures the average magnitude of prediction error and it is calculated following Equation (4.0). Like MAE, root mean square error (RMSE) is also used to measure the average magnitude of prediction error but it gives errors with larger absolute values more weight than errors with smaller absolute values and it is calculated following Equation (4.1). Willmott's

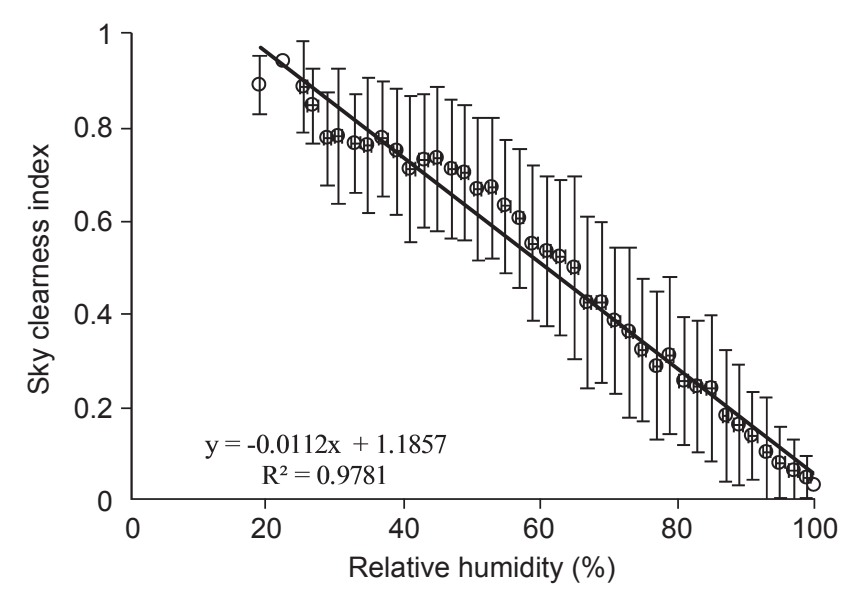

Note: Error bars represent one standard deviation.

Figure 2. Linear relationship between measured relative humidity (RH) and sky clearness index between 2015 to 2016 for five stations located in Malaysia $(N=25548)$. Solid line represents fitted linear regression line. Opened circle represents measured $R H$. 
index of agreement measures the degree of model prediction error and varies between 0 and 1 . A computed value of 1 indicates a perfect agreement between predicted and observed values while 0 indicates no agreement at all (Willmott and Matsuura, 2005), and it is calculated following Equation (4.2). A more accurate model would give MAE and RMSE close to zero but $d$ should approach one as closely as possible.

$$
\begin{aligned}
& \text { MAE }=\frac{1}{\mathrm{n}} \sum_{i=1}^{\mathrm{n}}\left|O_{i}-P_{i}\right| \\
& \text { RMSE }=\sqrt{\frac{1}{\mathrm{n}} \sum_{i=1}^{\mathrm{n}}\left[\left|O_{i}-P_{i}\right|\right]^{2}} \\
& d=1-\frac{\sum_{i=1}^{\mathrm{n}}\left|O_{i}-P_{i}\right|}{\sum_{i=1}^{\mathrm{n}}\left(\left|P_{i}-\bar{O}\right|+\left|O_{i}-\bar{O}\right|\right)}
\end{aligned}
$$

where $O_{i}$ is the measured values, $P_{i}$ is the estimated values and $\overline{0}$ is the averaged measured variable.

\section{RESULTS}

\section{Air Temperature}

Air temperatures for any time of day can be estimated by Equations (1.0) and (1.1). However, to assess the accuracy of the model, the observed and estimated hourly temperatures for the period from 1 August 2015 to 31 July 2017 were used to compute MAE, RMSE and d. Figure 3 shows that the fitted air temperature model reproduced observed hourly temperature data for the six stations very well. The MAE, RMSE and $d$ for the six stations ranged between $0.5^{\circ} \mathrm{C}-0.7^{\circ} \mathrm{C}, 0.6^{\circ} \mathrm{C}-1.0^{\circ} \mathrm{C}$ and $0.81-0.86$, respectively (Table 3). The low values of MAE and RMSE, and high agreement between observed and estimated hourly air temperature for the six stations suggest that the air temperature model could be used to generate hourly air temperature from daily minimum and maximum temperatures in the six major oil palm growing areas. Figure 4 gives an example of the goodness of fit of the model for a specific duration at Bukit Selarong weather station. It is obvious that the model simulated hourly air temperature reasonably close to the measured values on clear sky days ( 1 and

TABLE 3. MEAN ABSOLUTE ERROR (MAE), ROOT MEAN SQUARE ERROR (RMSE)

\begin{tabular}{|c|c|c|c|c|}
\hline Station & $n$ & MAE & RMSE & $d$ \\
\hline \multicolumn{5}{|l|}{ Air temperature $\left({ }^{\circ} \mathrm{C}\right)$} \\
\hline Bukit Selarong & 17545 & 0.5 & 0.6 & 0.86 \\
\hline Seri Intan & 16757 & 0.5 & 0.7 & 0.84 \\
\hline Dusun Durian & 15056 & 0.5 & 0.8 & 0.84 \\
\hline Diamond Jubilee & 17246 & 0.7 & 0.9 & 0.81 \\
\hline Ulu Remis & 16428 & 0.6 & 0.7 & 0.82 \\
\hline Imam & 17213 & 0.7 & 1.0 & 0.81 \\
\hline \multicolumn{5}{|l|}{ Relative humidity (\%) } \\
\hline Bukit Selarong & 17545 & 1.1 & 1.4 & 0.93 \\
\hline Seri Intan & 16757 & 1.8 & 2.0 & 0.88 \\
\hline Dusun Durian & 15056 & 0.8 & 1.0 & 0.93 \\
\hline Diamond Jubilee & 17246 & 1.2 & 2.0 & 0.92 \\
\hline Ulu Remis & 16428 & 1.1 & 1.3 & 0.93 \\
\hline Imam & 17213 & 1.5 & 1.8 & 0.90 \\
\hline \multicolumn{5}{|l|}{ Solar irradiance $\left(\mathrm{W} \mathrm{m}^{-2}\right)$} \\
\hline Bukit Selarong & 8760 & 120 & 157 & 0.71 \\
\hline Seri Intan & 8586 & 133 & 178 & 0.69 \\
\hline Dusun Durian & 8612 & 139 & 176 & 0.66 \\
\hline Diamond Jubilee & 8465 & 114 & 154 & 0.71 \\
\hline Ulu Remis & 7644 & 112 & 153 & 0.71 \\
\hline Imam & 8761 & 83 & 109 & 0.75 \\
\hline
\end{tabular}
AND INDEX OF AGREEMENT ( $d$ ) COMPUTED FOR HOURLY AIR TEMPERATURE, RELATIVE HUMIDITY AND SOLAR IRRADIANCE 
4 August) but the model could not simulate sudden drop in air temperature due to cloudy (2 August) or raining conditions ( 3 and 5 August). This is expected because the air temperature model is developed to simulate hourly air temperature according to average diurnal pattern.

\section{RH}

The RH model estimated hourly RH for all six stations with good level of accuracy. The MAE, RMSE and $d$ computed for the period from 1 August 2015 to 31 July 2017 were given in Figure 5 and Table 3. The MAE, RMSE and $d$ for the six stations ranged between $0.8 \%-1.5 \%, 1.0 \%-2.0 \%$ and $0.88-0.93$, respectively. The low values of MAE and
RMSE, and high agreement between observed and estimated hourly RH for the six stations suggest that the RH model could be used to generate hourly $\mathrm{RH}$ in the six major oil palm growing areas provided mean dew point temperature and observed hourly air temperature are available. In order to test the robustness of RH model, hourly RH was simulated using four different combinations of air and dew point temperatures. The combinations are: i) observed hourly air temperature with observed hourly dew point temperature; ii) observed hourly air temperature with mean dew point temperature; iii) simulated hourly air temperature with observed hourly dew point temperature; and iv) simulated hourly air temperature with mean dew point temperature.
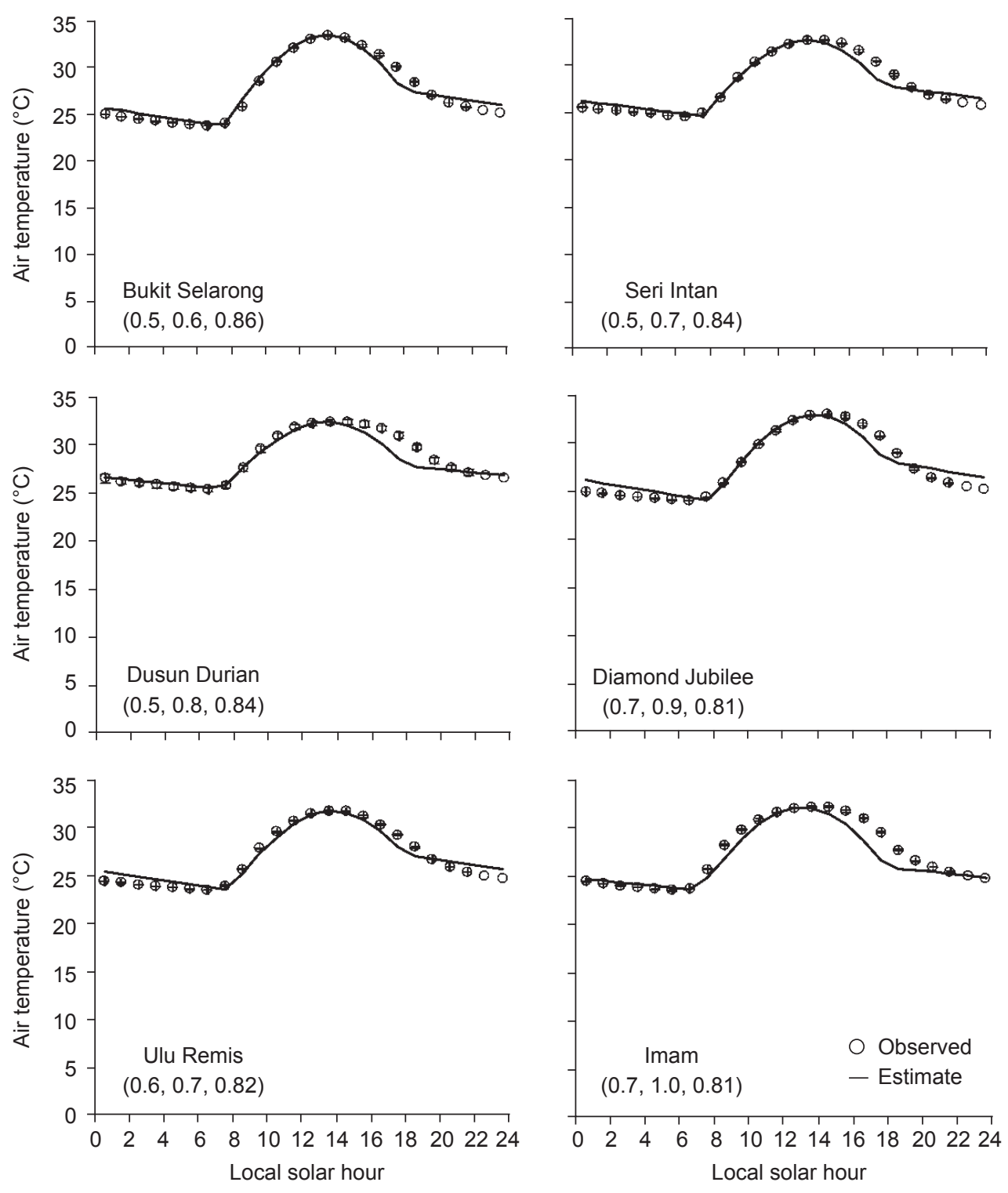

Figure 3. Comparison between model simulations and observations for hourly air temperature for six weather stations located at major oil palm growing areas. Values in brackets denote (MAE, RMSE, d), where MAE is the mean absolute error, RMSE is the residual mean squared error and $d$ is the index of agreement. All MAE and RMSE values are in ${ }^{\circ} \mathrm{C}$. Data presented are mean of individual hourly measurements $(n=15056-17545)$. Error bars represent one standard deviation. 
The goodness of fit of the RH model tested using the four different combinations of air and dew point temperatures for a specific duration at all six weather stations was given in Figures $6 a$ to $6 d$. The model simulated hourly RH very well if observed hourly air and dew point temperatures are used to compute air vapour pressure [Equation (2.0)] and air saturated vapour pressure [Equation (2.2)] (Figure 6a). However, the goodness of fit between observed and simulated RH declined when simulated hourly air temperature and mean dew point temperature were used to compute RH (Figure $6 b)$. The goodness of fit improved when simulated hourly air temperature and observed hourly dew point temperature were used to compute RH (Figure $6 c$ ). The goodness of fit was further improved when observed hourly air temperature and mean dew point temperature were used (Figure 6d). The sensitivity of RH model to air temperature was clearly illustrated when the model failed to simulate sudden surge in RH due to cloudy (2 August) and raining conditions (3 August) as observed at Bukit Selarong weather station. This is because higher simulated air temperature was used to compute $\mathrm{RH}$ instead of the lower observed air temperature (Figure 4). The comparison highlights the importance of having observed hourly air temperature or accurate estimate of hourly air temperature in deriving reliable hourly $\mathrm{RH}$. On the other hand, dew point temperature has less influence on the estimation of hourly RH.

\section{Solar Irradiance}

The solar irradiance model estimated hourly total solar irradiance for all six stations with less than satisfactory level of accuracy. The MAE, RMSE, and $d$ for all six stations ranged between $83-139 \mathrm{~W} \mathrm{~m}^{-2}, 109$ $178 \mathrm{~W} \mathrm{~m}^{-2}$ and $0.66-0.75$, respectively (Figure 7 and
Table 3). The RMSE values were higher and $d$ values were lower compared to Al Riza et al. (2011). They showed that their model calibrated and validated at the Universiti Teknologi Petronas Malaysia $\left(4.082^{\circ} \mathrm{N}\right.$; $100.992^{\circ} \mathrm{E}$ ) was reasonably good in estimating hourly total solar irradiance with RMSE value of $88 \mathrm{~W} \mathrm{~m}^{-2}$ and $d$ value of 0.97 , respectively. The high MAE and RMSE values and low $d$ values obtained in the present study indicate that the measured hourly total solar irradiance datasets contained considerable number of outliers. The outliers could be caused by thunderstorm or cloud cover which cause sudden drop in solar irradiance. The model evaluated here, though could account for the attenuation effect of thunderstorm and cloudiness on solar irradiance but it tends to underestimate the attenuation effect and overestimates solar irradiance. This partly explains the deviations between measured and estimated hourly total solar irradiance. As an example, Figure 8 shows that the solar irradiance model simulated hourly total solar irradiance fairly well during clear sky days but overestimated hourly total solar irradiance under raining condition.

Apart from outliers caused by thunderstorm or cloud cover, it was clear from the scatterplots that the model tends to slightly underestimate hourly total solar irradiance around noon hours as illustrated in Figure 8. Underestimation of hourly total solar irradiance around noon hours may be attributable to the vertical variability of water vapour in the atmosphere (Gueymard, 2014), which was not accounted for by the model. It is, thus, clear that the effect of vertical variability of water vapour on attenuation of solar radiation under local conditions need to be elucidated in order to further improve the accuracy of the present model. If very accurate solar irradiance data is critical, the results indicate direct measurement of hourly solar irradiance may be necessary.

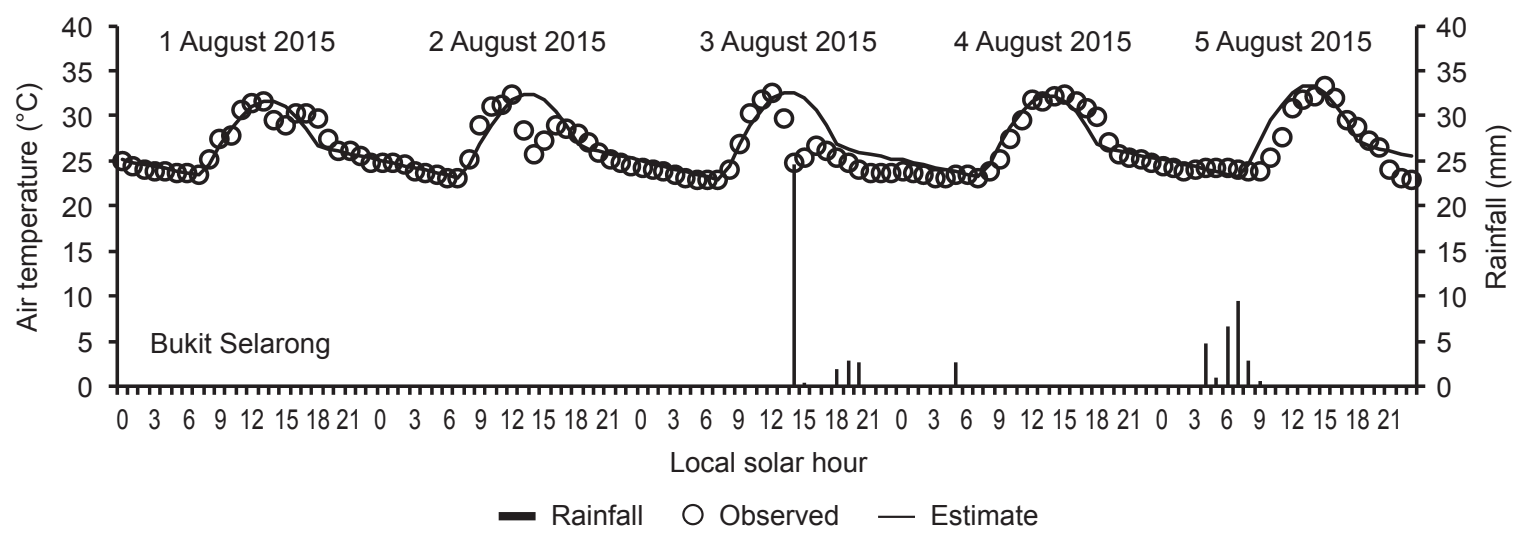

Figure 4. Observed and simulated hourly air temperatures and rainfall distributions at the Bukit Selarong weather station, Kulim. Observed hourly air temperature and rainfall data shown were recorded from 1 to 5 August 2015. 

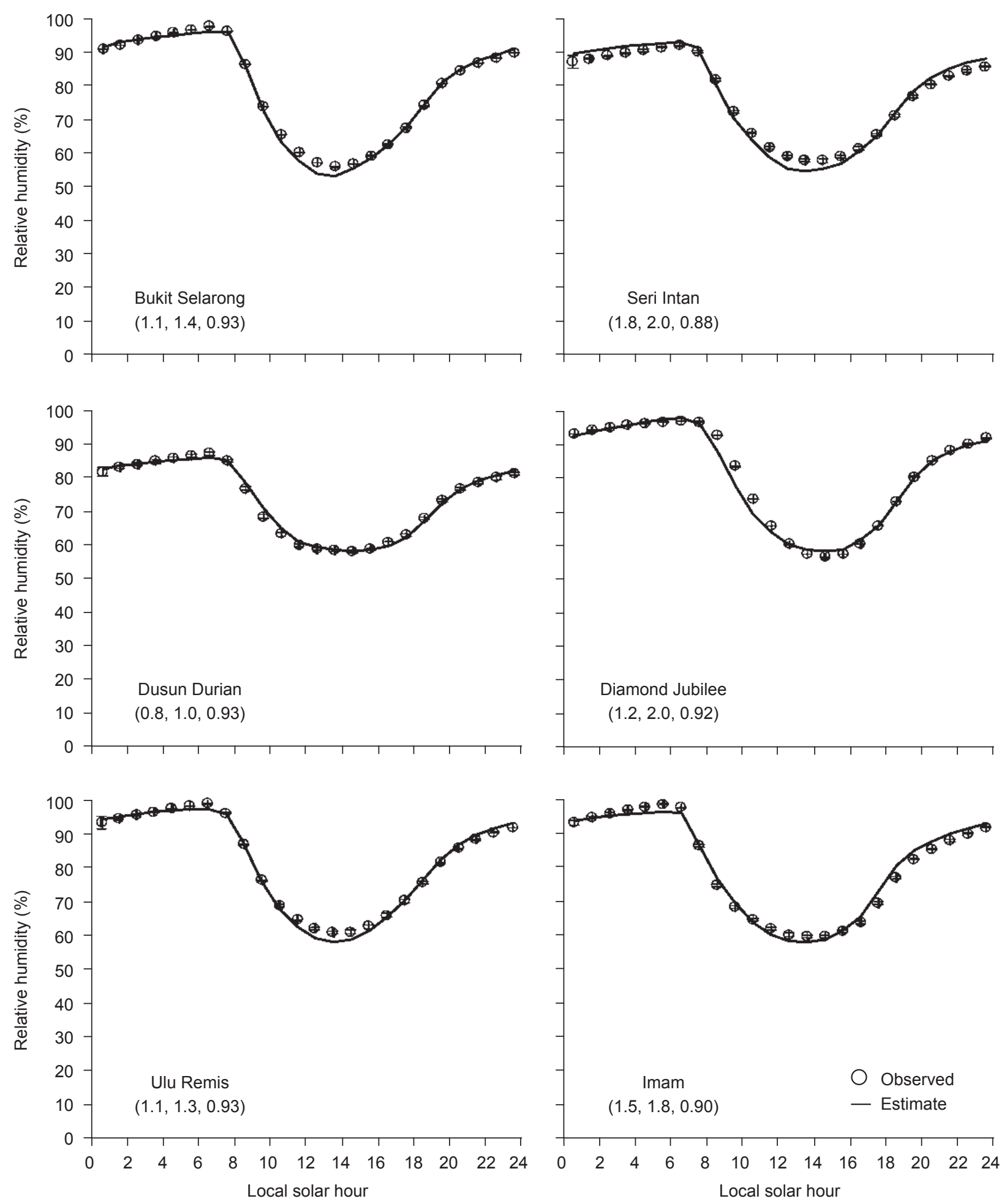

Figure 5. Comparison between model simulations and observations for hourly relative humidity $(R H)$ for six weather stations located at major oil palm growing areas. Hourly RH was computed using actual hourly air temperature and mean dew point temperature. Values in brackets denote (MAE, RMSE, d), where MAE is the mean absolute error, RMSE is the residual mean squared error and $d$ is the index of agreement. All MAE and RMSE values are in \%. Data presented are mean of individual hourly measurements $(n=15056-17545)$. Error bars represent one standard deviation. 

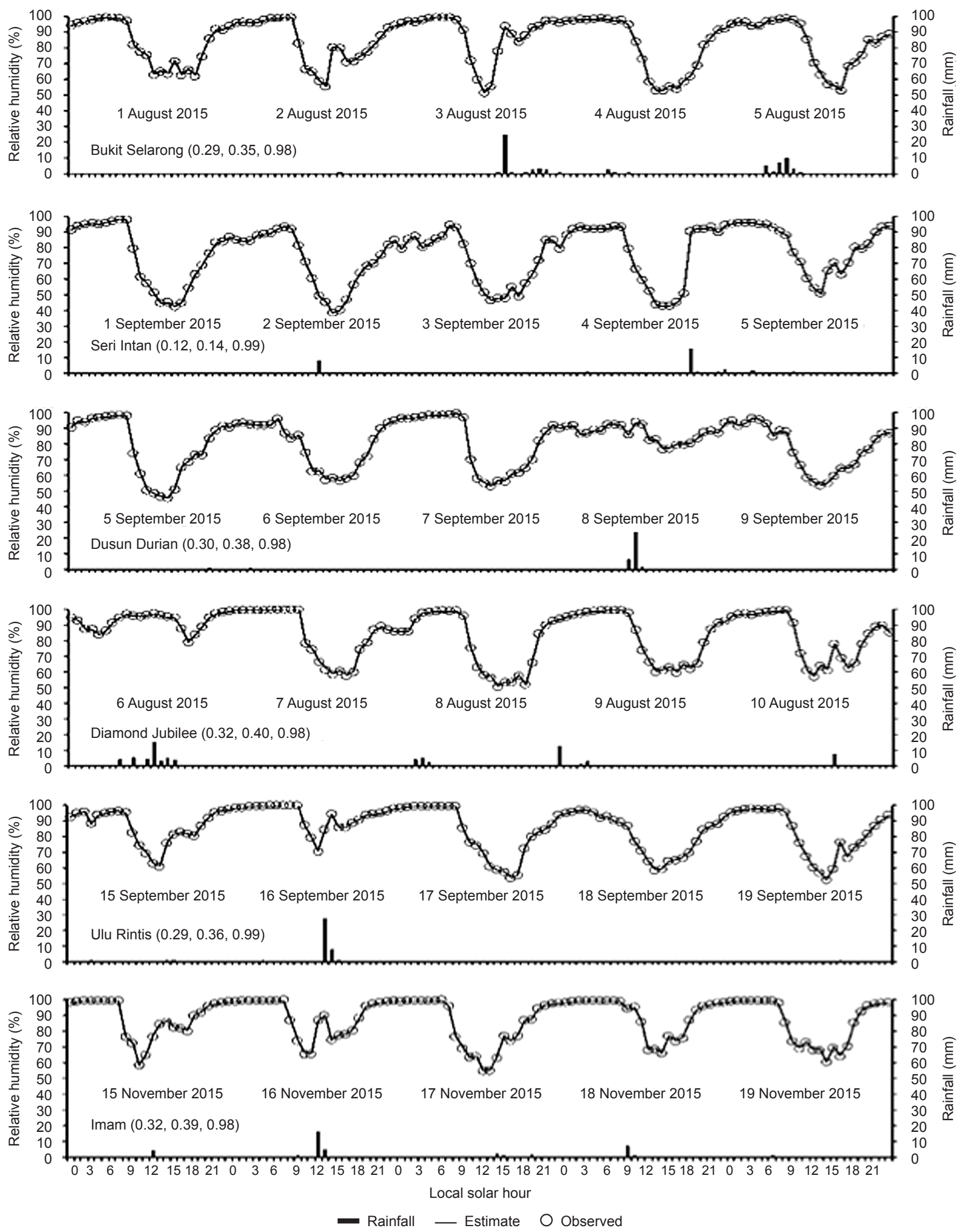

Figure 6a. Observed and simulated hourly relative humidity $(R H)$ and rainfall distributions at six weather stations located at major oil palm growing areas. Simulated hourly RH was computed using observed hourly air temperature and hourly dew point temperature. Values in brackets denote (MAE, RMSE, d), where MAE is the mean absolute error, RMSE is the residual mean squared error and $d$ is the index of agreement. All MAE and RMSE values are in \%. 

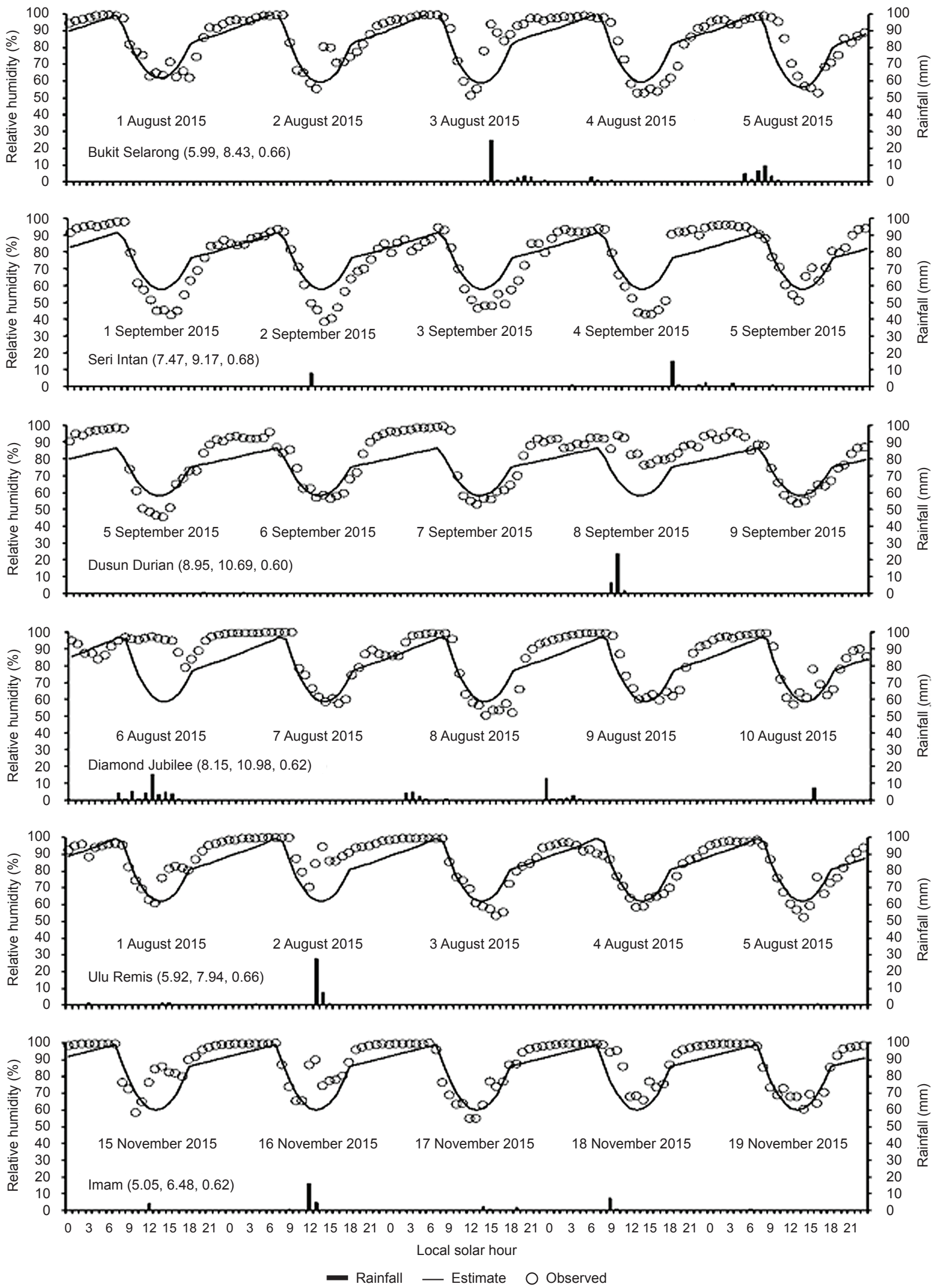

Figure 6b. Observed and simulated hourly relative humidity $(R H)$ and rainfall distributions at six weather stations located at major oil palm growing areas. Simulated hourly $R H$ was computed using simulated hourly air temperature and mean dew point temperature. Values in brackets denote (MAE, RMSE, d), where MAE is the mean absolute error, RMSE is the residual mean squared error and $d$ is the index of agreement. All MAE and RMSE values are in $\%$. 

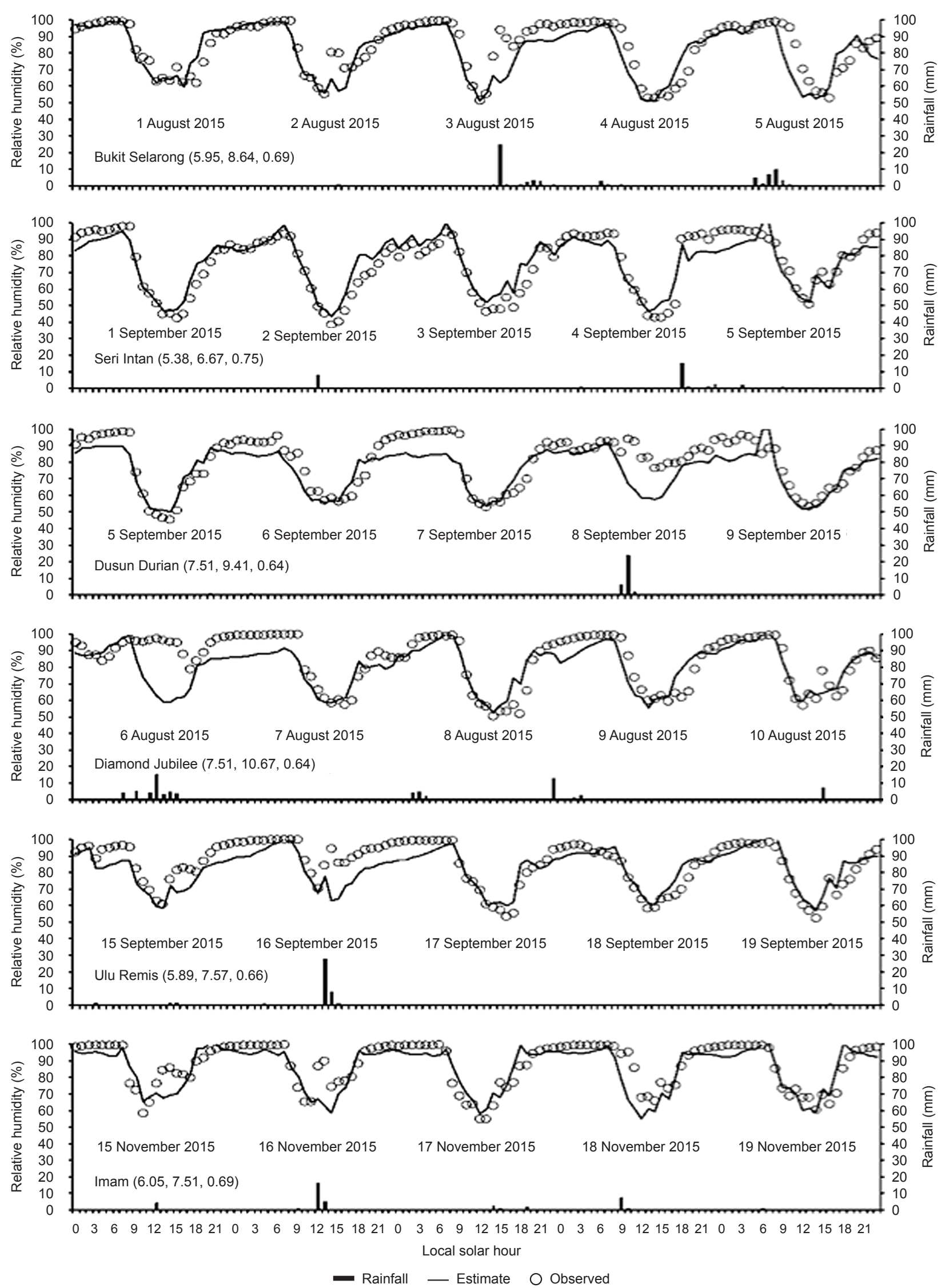

Figure 6c. Observed and simulated hourly relative humidity $(R H)$ and rainfall distributions at six weather stations located at major oil palm growing areas. Simulated hourly RH was computed using simulated hourly air temperature and observed hourly dew point temperature. Values in brackets denote (MAE, RMSE, d), where MAE is the mean absolute error, RMSE is the residual mean squared error and dis the index of agreement. All MAE and RMSE values are in $\%$. 

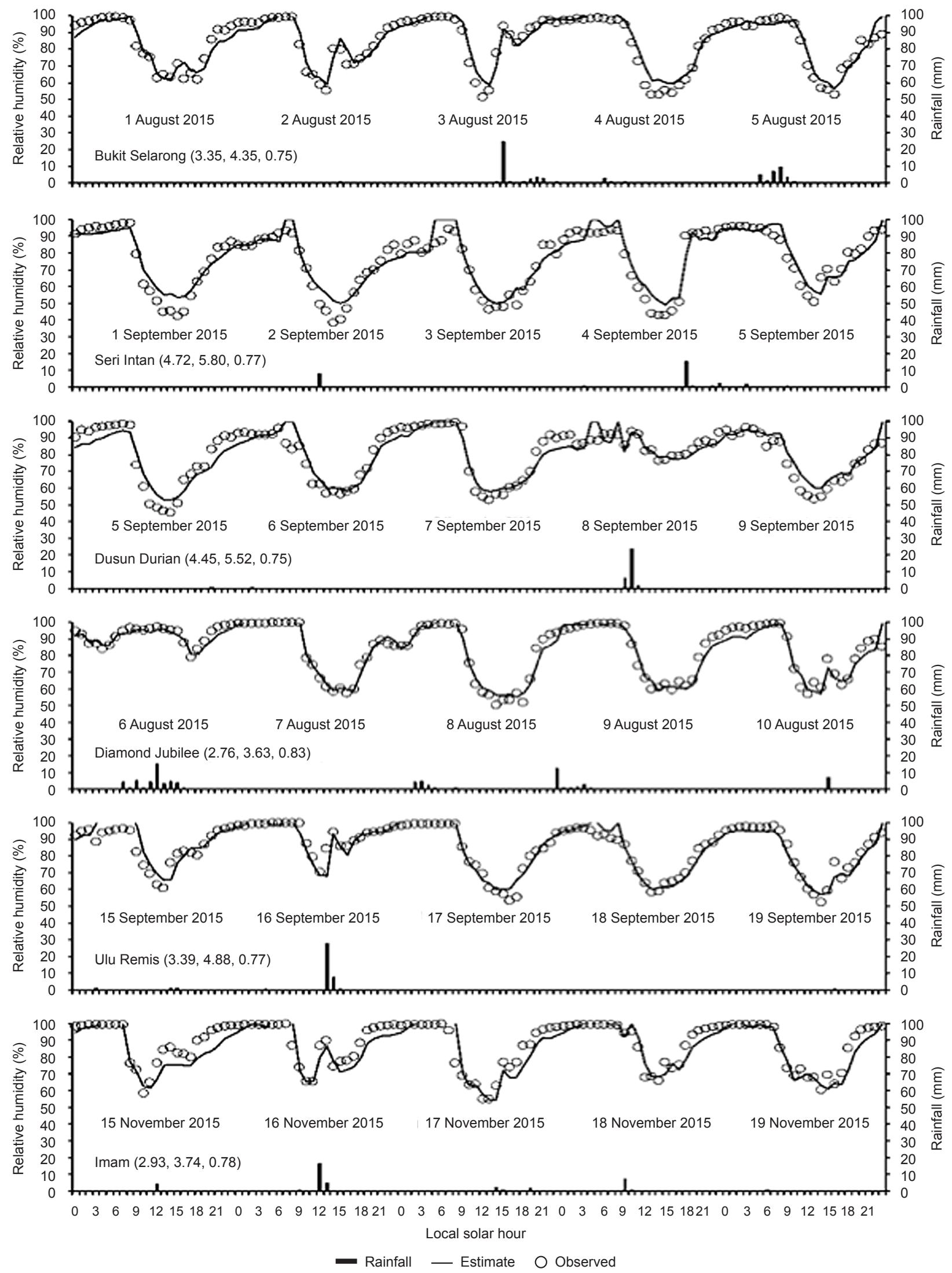

Figure $6 d$. Observed and simulated hourly relative humidity $(R H)$ and rainfall distributions at six weather stations located at major oil palm growing areas. Simulated hourly RH was computed using observed hourly air temperature and mean dew point temperature. Values in brackets denote (MAE, RMSE, d), where MAE is the mean absolute error, RMSE is the residual mean squared error and $d$ is the index of agreement. All MAE and RMSE values are in $\%$. 

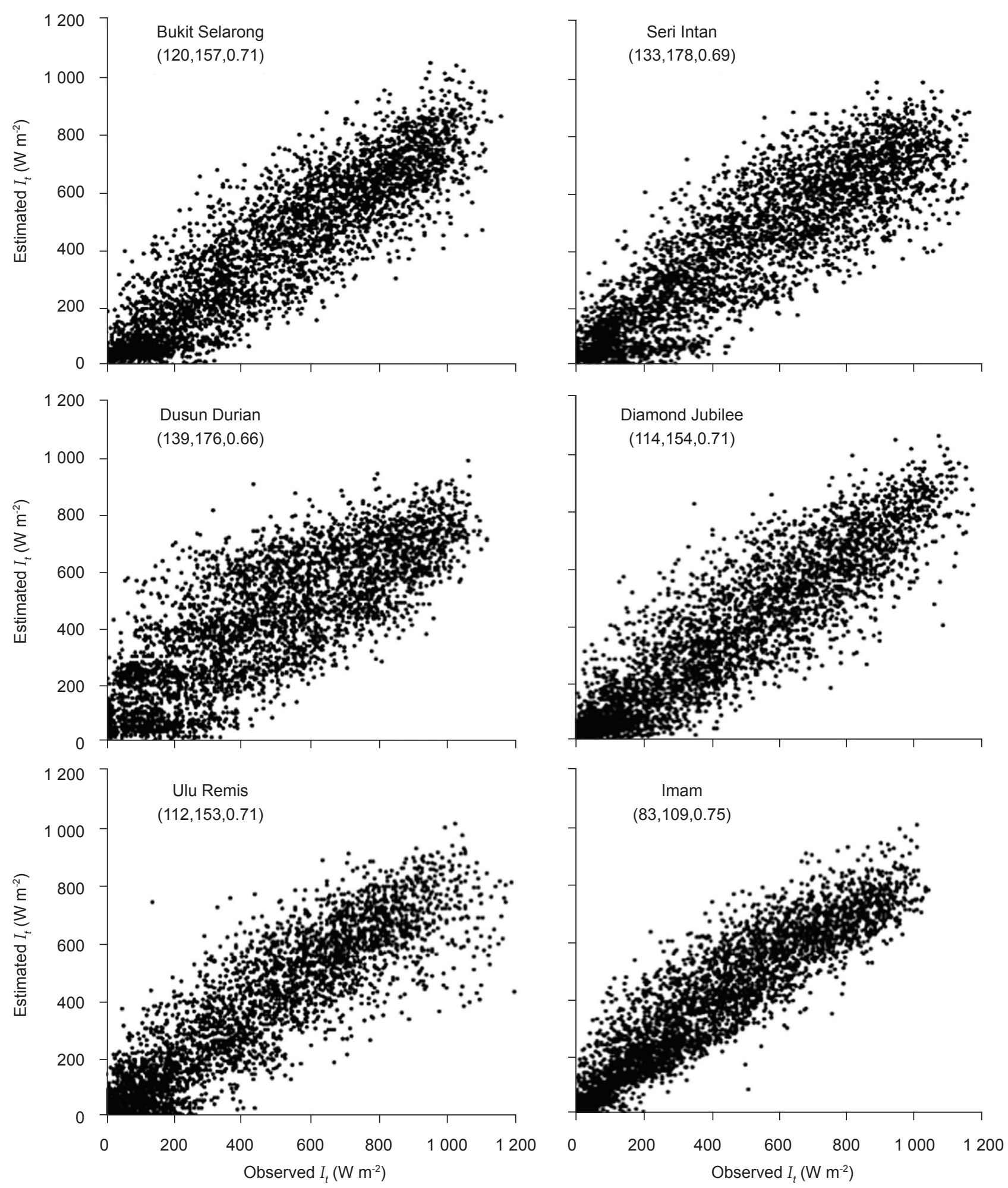

Figure 7. Comparison between model simulations and observations for hourly total solar irradiance for six weather stations located at major oil palm growing areas. Values in brackets denote (MAE, RMSE, $d$ ), where MAE is the mean absolute error, RMSE is the residual mean squared error and $d$ is the index of agreement. All MAE and RMSE values are in $W m^{-2}$. Data presented are individual hourly measurements $(n=7644-8761)$. 


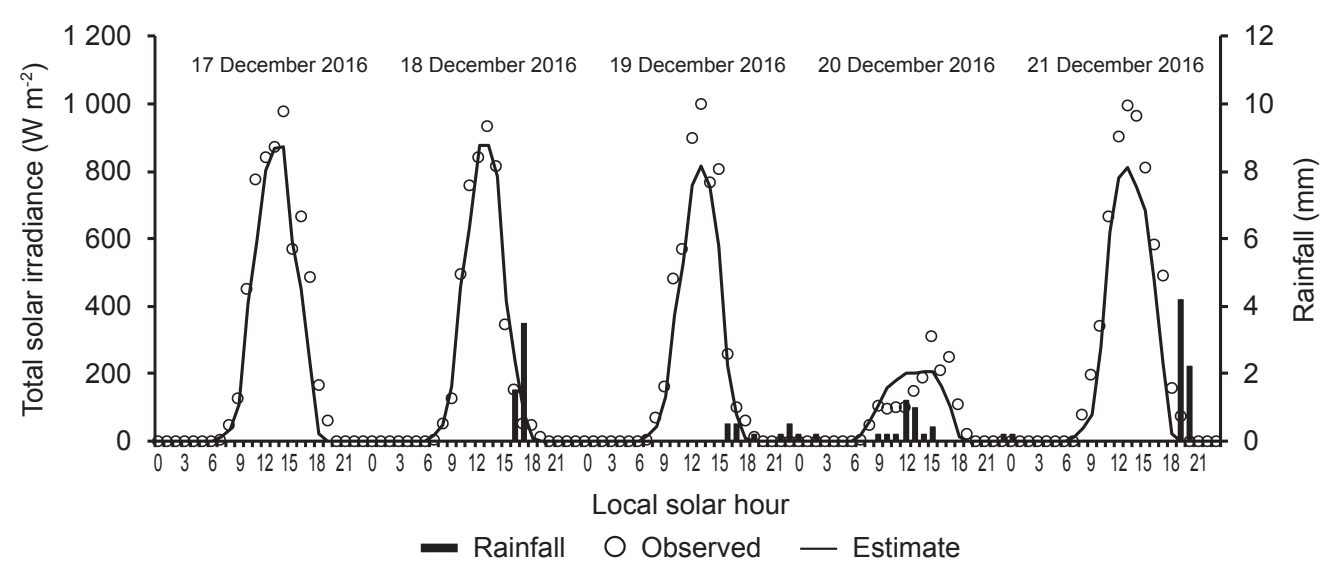

Figure 8. Observed and simulated hourly total solar irradiance and rainfall distributions at the Bukit Selarong weather station, Kulim, Kedah, Malaysia. Observed hourly total solar irradiance shown were recorded during clear sky days (17, 18, 19 and 21 December 2016) and raining day (20 December 2016). Simulated hourly total solar irradiance data were computed using observed hourly relative humidity.

\section{DISCUSSION}

Vapour pressure deficit (VPD) and solar irradiance have been shown to affect photosynthesis and transpiration of oil palm (Smith, 1989; Henson and Chang, 1990; Dufrene and Saugier, 1993; Kallarackal, 1996; Suresh et al., 2012). Hence, accurate estimation of VPD (as indicated by RH) and solar irradiance is important. The present study showed that VPD can be accurately estimated by having accurate hourly air temperature as model input. Accurate hourly air temperature can be obtained through direct measurement or simulation using the air temperature model evaluated here. If simulated air temperature is used, one should expect higher air temperature being estimated during cloudy or raining condition which would result in higher VPD being estimated. High VPD would reduce photosynthetic and transpiration rate of oil palm leaf (Smith, 1989; Henson and Chang, 1990; Dufrene and Saugier, 1993; Kallarackal, 1996; Suresh et al., 2012), thus underestimating dry matter production. However, during cloudy or raining condition, solar irradiance is more limiting than VPD. Hence, it appears that overestimating VPD during cloudy or raining condition would cause negligible effect on photosynthesis and dry matter production.

The accuracy of the solar irradiance model evaluated here is at best satisfactory only. The model tends to overestimate hourly total solar irradiance particularly during cloudy and raining conditions and underestimates hourly total solar irradiance during clear sky condition. This appears to be a major setback in the present solar irradiance model. Underestimating total solar irradiance during clear sky condition might seem to cause insignificant effect on dry matter production since photosynthesis of oil palm leaf would remain light-saturated as long as photosynthetic photon flux density is above $1000 \mu \mathrm{mol} \mathrm{m} \mathrm{m}^{-2} \mathrm{~s}^{-1}$, roughly equivalent to a total solar irradiance of $480 \mathrm{~W} \mathrm{~m}^{-2}$ (Dufrene and Saugier, 1993; Kallarackal, 1996). The simulated total solar irradiance during clear sky condition is always well above $480 \mathrm{~W} \mathrm{~m}^{-2}$. However, higher solar irradiance might result in greater light levels across canopy depth, thus canopy photosynthesis would likely be higher. In this case, dry matter production would be underestimated. On the other hand, overestimating total solar irradiance during cloudy or raining condition would lead to overestimating dry matter production since photosynthesis of oil palm would be overestimated due to higher solar irradiance being intercepted by the oil palm leaves. It is, thus, obvious that higher errors in modelling photosynthesis and dry matter production is expected if simulated solar irradiance is used as model input.

Air temperature in most parts of Malaysia has increased over the last 40 years at rates of $0.27^{\circ} \mathrm{C}$ to $0.40^{\circ} \mathrm{C}$ per 10 years (Tangang and Juneng, 2007) and was projected to increase by $1.5^{\circ} \mathrm{C}$ to $2.0^{\circ} \mathrm{C}$ by 2050 (Paterson et al., 2015). As air temperature increases, $\mathrm{RH}$ is expected to decrease with concomitant increase in VPD. High VPD would reduce photosynthetic and transpiration rate of oil palm leaf (Smith, 1989; Henson and Chang, 1990; Dufrene and Saugier, 1993; Kallarackal, 1996; Suresh et al., 2012), hence reducing dry matter required for fresh fruit bunch (FFB) production. FFB yields of oil palm are projected to decrease by approximately $30 \%$ should temperature increase $2^{\circ} \mathrm{C}$ above optimum and rainfall decrease by $10 \%$ (Siwar et al., 2013). With increasing weather anomalies projected in the near future (Paterson et al., 2015), studies on relating FFB production to weather variables have gained momentum recently (Shanmuganathan and Narayanan, 2012; Siwar et al., 2013; Shanmuganathan et al., 2014; Paterson et al., 2015; Oettli et al., 2018; Teh and Cheah, 2018). Though, the effects of weather variables such as rainfall, temperature, solar radiation and $\mathrm{RH}$ or VPD on FFB yields have been studied previously 
(Robertson and Foong, 1976; Foong, 1982; Chan, 1991; Caliman and Southworth, 1998; Henson, 2000). These studies were mainly confined to regional scale or at specific locations where weather data are available. Studies at regional scale or at specific locations might fail to elucidate the interacting effects of weather variables on physiological processes that drive FFB production in Malaysia (Oettli et al., 2018) because more granular time scale such as hourly or daily weather data are often required. Weather data at such granularity scale are very scarce in most oil palm growing areas in Malaysia. The solar irradiance, temperature and $\mathrm{RH}$ models developed in the present study could be used as alternatives to generate hourly solar irradiance, air temperature and $\mathrm{RH}$ in oil palms growing areas where observed weather data are not available.

\section{CONCLUSION}

In crop growth simulation models, weather variables such as air temperature, $\mathrm{RH}$ and solar irradiance are often used as input to drive photosynthesis and evapotranspiration. Accurate estimation of these variables in situations where data are missing or in areas where data are not available is, thus of considerable significance. The present study, using hourly air temperature, dew point temperature, $\mathrm{RH}$ and solar irradiance data collected from six widely distributed weather stations in Malaysia, has shown that it is feasible to estimate hourly air temperature, $\mathrm{RH}$ and solar irradiance by modifying or calibrating published weather models. These models thus could be used to estimate hourly air temperature, $\mathrm{RH}$ and solar irradiance in the six major oil palm growing areas in Malaysia. However, should more accurate hourly weather data be needed for crop growth simulation, direct measurement of these weather variables is required.

\section{ACKNOWLEDGEMENT}

The authors would like to thank Sime Darby Plantation Berhad for providing weather data without which the present study would not be accomplished. The authors are grateful to Dr R H V Corley for his critical review on the manuscript and his valuable comments. Special thanks go to Premkumar Tamilarasan, Lai Guan Yi, Norhayati Abdullah and Siti Aishah Abdul Wahid for their assistance in maintaining the weather stations and retrieving the weather data.

\section{REFERENCES}

Al Riza, D F; Gilani, S I H and Aris, M S (2011). Hourly solar radiation estimation using ambient temperature and relative humidity data. International J. Environmental Science and Development, 2: 3.
Bristow, K L and Campbell, G S (1984). On the relationship between incoming solar radiation and daily maximum and minimum temperature. Agricultural and Forest Meteorology, 31(2): 159-166.

Caliman, J P and Southworth, A (1998). Effect of drought and haze on the performance of oil palm. Proc. of the 1998 Int. Oil Palm Conf. - Commodity of the Past, Today and the Future (A. Jatmika et al., eds.). Indonesian Oil Palm Research Institute, Medan, Indonesia. $40 \mathrm{pp}$.

Chan, K W (1991). Predicting oil palm yield potential based upon solar radiation. Paper presented at the $2^{\text {nd }}$ National Seminar on Agrometeorology, Meteorological Department Malaysia, Petaling Jaya.

De Wit, C T; Goudriaan, J and Van Laar, H H (1978). Simulation of Simulation. Respiration and Transpiration of Crops. Pudoc, Wageningen, The Netherlands. 148 pp.

Desa, M N and Rakhecha, P R (2006). Deriving the highest persisting monthly 24-hour dew points in Malaysia for the estimation of PMP. Climate Variability and Change - Hydrological Impacts. Proc. of the Fifth FRIEND World Conference. Havana, Cuba, November 2006. IAHS Publ. 308.

Dufrêne, E and Saugier, B (1993). Gas exchange of oil palm in relation to light, vapour pressure deficit, temperature and leaf age. Functional Ecology, 7: 97104.

Ephrath, J E; Goudriaan, J and Marani, A (1996). Modelling diurnal patterns of air temperature, radiation, wind speed and relative humidity by equations from daily characteristics. Agricultural Systems, 51: 377-393.

Floyd, R B and Braddock, R D (1984). A simple method for fitting average diurnal temperature curves. Agricultural and Forest Meteorology, 32: 107119.

Foong, S F (1982). An improved weather-based model for estimating oil palm fruit yield. The Oil Palm in Agriculture in the Eighties (Pushparajah, E and Chew, P S eds.). Vol. 1. Incorporated Society of Planters, Kuala Lumpur. p. 327-349.

Gueymard, CA (2014). Impact of on-site atmospheric water vapor estimation methods on the accuracy of local solar irradiance predictions. Solar Energy, 101: 74-82.

Henson, I E (2000). Modelling the effects of 'haze' on oil palm productivity and yield. J. Oil Palm Res. Vol. 12: 123-134. 
Henson, I E and Chang, K C (1990). Evidence for water as a factor limiting performance of field palms in West Malaysia. Proc. of the 1989 International Palm Oil Development Conference. Module II - Agriculture. PORIM, Bangi. p. 487-498.

Kallarackal, J (1996). Water relations and photosynthesis of the oil palm in Peninsular India. KFRI Research Report 110. Kerala Forest Research Institute, Peechi, Thrissur.

Kaplanis, S and Kaplani, E (2007). A model to predict expected mean and stochastic hourly global solar radiation values. Renewable Energy, 32: 141425.

Kimball, B A and Bellamy, L A (1986). Generation of diurnal solar radiation, temperature, and humidity patterns. Energy in Agriculture, 5(3): 185-197.

Oettli, P; Behera, S K and Yamagata, T (2018). Climate based predictability of oil palm tree yield in Malaysia. Scientific Reports, 8: 2271.

Paterson, R R M; Kumar, L; Taylor, S and Lima, N (2015). Future climate effects on suitability for growth of oil palms in Malaysia and Indonesia. Scientific Reports, 5: 14457.

Robertson, G W and Foong, S F (1977). Weatherbased yield forecasts for oil palm fresh fruit bunches. International Developments in Oil Palm (Earp, D A and Newall, W eds.). Incorporated Society of Planters, Kuala Lumpur. p. 695-709.

Shanmuganathan, S and Narayanan, A (2012). Modelling the climate change effects on Malaysia's oil palm yield. https:/ / doi.org/10.1109/IS3e.2012. 6414948

Shanmuganathan, S; Narayanan, A and Mohamed, M (2014). A hybrid approach to modelling the climate change effects on Malaysia's oil palm yield at the regional scale. Recent Advances on Soft Computing and Data Mining (Herawan, T; Ghazali, R and Deris, M M eds.). Cham, Switzerland: Springer. p. 335-345.

Siwar, C; Ahmed, F and Begum, R A (2013). Climate change, agriculture and food security issues: Malaysian perspective. J. Food, Agriculture and Environment, 11(2): 1118-1123.
Suresh, K; Kumar, M K; Kanitha, D L; Lakshimi, R P and Kumar, K S (2012). Variations in photosynthetic parameters and leaf water potential in oil palm grown under two different moisture regimes. Indian J. Plant Physiology, 17 (3\&4): 233-240.

Smith, B G (1989). The effects of soil water and atmospheric vapour pressure deficit on stomatal behaviour and photosynthesis in the oil palm. J. Experimental Botany, 40: 647-651.

Tang, C K and Chin, N (2012). Chapter 2: Malaysia's weather data. Building Energy Efficiency Technical Guideline for Passive Design. 196 pp.

Tangang, F T and Juneng, L (2007). Climate variability, climate change and extreme weather events in Malaysia. National Seminar on SocioEconomic Impacts of Extreme Weather and Climate Change. Malaysian Meteorological Department Ministry.

Teh, C B S and Cheah, S S (2018). Modelling crop growth and yield in palm oil cultivation. Achieving Sustainable Cultivation of Oil Palm Volume 1: Introduction, Breeding and Cultivation Techniques (Alain Rival ed.). Burleigh Dodds Series in Agricultural Science. p. 1-45.

Waichler, S R and Wigmosta, M S (2003). Development of hourly meteorological values from daily data and significance to hydrological modeling at H. J. Andrews Experimental Forest. J. Hydrometeorology, 4: 251-263.

Wann, M; Yen, D and Gold, H J (1985). Evaluation and calibration of three models for daily cycle of air temperature. Agricultural and Forest Meteorology, 34: 121-128.

Wilkerson, G G; Jones, J W; Boote, K J; Ingram, K T and Mishoe, J W (1983). Modeling soybean growth for crop management. Transactions of the ASAE, 26: 63-73.

Willmott, C and Matsuura, K (2005). Advantages of the mean absolute error (MAE) over the root mean square error (RMSE) in assessing average model performance. Climate Research, 30: 79-82.

Yang, K and Koike, T (2002). Estimating surface solar radiation from upper-air humidity. Solar Energy, 72: 177-186. 